\title{
Do depression and pain intensity interfere with physical activity in daily life in patients with Chronic Low Back Pain?
}

Citation for published version (APA):

Huijnen, I. P. J., Verbunt, A. M. C. F., Peters, M. L., Delespaul, P. A. E. G., Kindermans, H. P. J., Roelofs, J., Goossens, M. E. J. B., \& Seelen, H. A. M. (2010). Do depression and pain intensity interfere with physical activity in daily life in patients with Chronic Low Back Pain? Pain, 150(1), 161-166. https://doi.org/10.1016/j.pain.2010.04.021

Document status and date:

Published: 01/07/2010

DOI:

10.1016/j.pain.2010.04.021

Document Version:

Publisher's PDF, also known as Version of record

\section{Document license:}

Taverne

Please check the document version of this publication:

- A submitted manuscript is the version of the article upon submission and before peer-review. There can be important differences between the submitted version and the official published version of record.

People interested in the research are advised to contact the author for the final version of the publication, or visit the DOI to the publisher's website.

- The final author version and the galley proof are versions of the publication after peer review.

- The final published version features the final layout of the paper including the volume, issue and page numbers.

Link to publication

\footnotetext{
General rights rights.

- You may freely distribute the URL identifying the publication in the public portal. please follow below link for the End User Agreement:

www.umlib.nl/taverne-license

Take down policy

If you believe that this document breaches copyright please contact us at:

repository@maastrichtuniversity.nl

providing details and we will investigate your claim.
}

Copyright and moral rights for the publications made accessible in the public portal are retained by the authors and/or other copyright owners and it is a condition of accessing publications that users recognise and abide by the legal requirements associated with these

- Users may download and print one copy of any publication from the public portal for the purpose of private study or research.

- You may not further distribute the material or use it for any profit-making activity or commercial gain

If the publication is distributed under the terms of Article 25fa of the Dutch Copyright Act, indicated by the "Taverne" license above, 


\title{
Do depression and pain intensity interfere with physical activity in daily life in patients with Chronic Low Back Pain?
}

\author{
Ivan P.J. Huijnen $^{\mathrm{a}, *}$, Jeanine A. Verbunt ${ }^{\mathrm{a}, \mathrm{b}, \mathrm{c}}$, Madelon L. Peters ${ }^{\mathrm{d}}$, Philippe Delespaul ${ }^{\mathrm{e}}$, \\ Hanne P.J. Kindermans ${ }^{\mathrm{d}}$, Jeffrey Roelofs ${ }^{\mathrm{d}}$, Marielle Goossens ${ }^{\mathrm{d}}$, Henk A.M. Seelen ${ }^{\mathrm{a}, \mathrm{b}}$ \\ a Department of Rehabilitation Medicine, Research School CAPHRI, Maastricht University, P.O. Box 616, 6200 MD Maastricht, The Netherlands \\ ${ }^{\mathrm{b}}$ Adelante Centre of Expertise in Rehabilitation and Audiology, P.O. Box 88, 6430 AB Hoensbroek, The Netherlands \\ ${ }^{\mathrm{C}}$ Department of General Practice, Research School CAPHRI, Maastricht University, P.O. Box 616, 6200 MD Maastricht, The Netherlands \\ ${ }^{\mathrm{d}}$ Department of Clinical Psychological Science, Maastricht University, P.O. Box 616, 6200 MD Maastricht, The Netherlands \\ ${ }^{\mathrm{e}}$ Mental Health E NeuroSciences (MHeNS), Maastricht University, P.O. Box 616, 6200 MD Maastricht, The Netherlands
}

\section{A R T I C L E I N F O}

\section{Article history:}

Received 17 October 2009

Received in revised form 25 March 2010

Accepted 19 April 2010

\section{Keywords:}

Chronic Low Back Pain

Activity-related behaviour

Accelerometry

Depression

Diary assessment

\begin{abstract}
A B S T R A C T
Patients with chronic pain may have difficulties estimating their own physical activity level in daily life. Pain-related factors such as depression and pain intensity may affect a patients' ability to estimate their own daily life activity level. This study evaluates whether patients with Chronic Low Back Pain (CLBP) who are more depressed and/or report more pain indeed have a lower objectively assessed daily life activity level or whether they only perceive their activity level as lower. Patients with CLBP were included in a cross-sectional study. During 14 days physical activity in daily life was measured, with both an electronic diary and an accelerometer. Multilevel analyses were performed to evaluate whether a higher level of depression and/or pain intensity was associated with a lower objectively assessed activity level or the discrepancy between the self-reported and objectively assessed daily life activity levels. Results, based on 66 patients with CLBP (mean RDQ score 11.8), showed that the objectively assessed daily life activity level is not associated with depression or pain intensity. There was a moderate association between the self-reported and objectively assessed activity levels $(\beta=0.39, p<0.01)$. The discrepancy between the two was significantly and negatively related to depression $(\beta=-0.19, p=0.01)$, indicating that patients who had higher levels of depression judged their own activity level to be relatively low compared to their objectively assessed activity level. Pain intensity was not associated with the perception of a patient's activity level $(\beta=0.12$, ns).
\end{abstract}

(c) 2010 International Association for the Study of Pain. Published by Elsevier B.V. All rights reserved.

\section{Introduction}

The main aim of many pain rehabilitation programs is to improve a patient's daily life functioning. However, patients with chronic pain often have difficulties estimating their own level of physical activity in daily life [17]. This is supported by studies in which a less pronounced association is found between physical activity based on self-report and objective movement registrations in patients with Chronic Low Back Pain (CLBP) [30,31], whereas other studies report moderate to high associations in healthy individuals [21,23]. For patients with CLBP, a daily life activity measurement based on self-report can result in an incorrect presentation of their actual activity level $[10,17]$.

In patients with chronic pain, several pain-related factors have been reported that have a negative influence on their self-reported

\footnotetext{
* Corresponding author. Tel.: +31 455282381; fax: +31 455282348

E-mail address: ivan.huijnen@maastrichtuniversity.nl (I.P.J. Huijnen).
}

daily life activities. In previous studies, depression and pain intensity were found to be negatively associated with a patient's self-reported activity level $[15,17]$. However, in studies using objective measures for daily life activities no significant associations were found [11,31]. Furthermore, in patients with CLBP who had a lower score on the mental health domain of the SF-36 quality of life scale, a lower level of physical functioning was found compared to patients with a higher score on mental health, in spite of a comparable level of objective performance in the laboratory [32]. It may therefore be hypothesized that patients with CLBP who are more depressed underestimate their daily life activity level. This means that although depression may be associated with the perception of the level of physical activity this may not be the case for objectively assessed daily life activity level. Another potential influencing factor for a patient's perception of their daily life activity level is pain intensity. Patients with higher levels of pain reported to be less physically active $[10,15]$. However, in other studies in which physical activity was assessed with objective measures such as 
accelerometry, physical capacity or physical performance measures, the association between physical activity and pain intensity appeared to be only weak or non-existent $[1,9,19,25,31]$.

In this study, we test whether patients with CLBP who are more depressed and/or experience more pain have indeed a lower level of objectively assessed activity in daily life or whether they only judge their activity level as lower. We predicted that especially the discrepancy between the self-reported and objectively measured activity level would be influenced by pain and depression, with patients reporting more severe pain and higher levels of depression showing a relative underestimation of their objectively assessed physical activity.

\section{Methods}

\subsection{Participants}

This study included a subset of patients participating in a longitudinal cohort study, aiming at defining different activity-related strategies in patients with CLBP and testing a new theoretical model in which the role of self-discrepancies in explaining these different types of activity-related strategies will be evaluated. Inclusion criteria for this study were (a) low back pain: pain localized below the scapulae and above the gluteal folds for longer than 3 months [20], (b) age between 18 and 65, (c) no specific cause or strong suspicion of a specific cause, such as lumbar disc herniation with neurological complaints, major structural back abnormality, evidence of inflammatory, systemic or neoplastic disease, (d) agreement to participate in a daily life study, measuring daily life activity with both an accelerometer and a diary for 14 days. Exclusion criteria were (a) pregnancy, (b) non-fluency in Dutch, and (c) serious psychiatric diseases. Patients in the cohort study were included in two different ways: 81 patients were referred by consultants in rehabilitation medicine in the Southern part of The Netherlands (one rehabilitation centre, six hospital departments of rehabilitation) and 35 patients responded to an advertisement in a local newspaper. In case patients responded to the advertisement the abovementioned selection criteria were checked by a consultant in rehabilitation medicine, who performed a medical screening according to the clinical guideline for low back pain of the Dutch College of General Practitioners [8]. The Medical Ethics Committee of the Maastricht University/University Hospital Maastricht, The Netherlands, approved the protocol.

\subsection{Measures}

\subsubsection{Disability}

Low back disability was assessed using the Roland Disability Questionnaire (RDQ) [26,27]. This questionnaire contains 24 items measuring limitations in different activities in daily life that can be answered by Yes or No. The item scores are summed resulting in total scores ranging from 0 to 24 , with higher scores reflecting higher levels of disability. The Dutch version of the RDQ has a high reproducibility and validity and is responsive to change $[5,12,18]$.

\subsubsection{Habitual physical activity in daily life}

To score the habitual physical activity level, which reflects the level of daily life activities during the last year, the Baecke Physical Activity Questionnaire (BPAQ) was used [2]. The BPAQ consists of three indices of habitual physical activity: the occupational activity index; sport activity index and the leisure time index. The reliability of the BPAQ in patients with LBP appears to be sufficient [16].

\subsubsection{Pain intensity}

Pain intensity was measured with three $100 \mathrm{~mm}$ Visual Analogue Scales (VAS; [24]). Patients were asked to rate their actual pain (at that moment) and their highest and lowest pain levels of the past week on three separate VAS scales. The mean of the three VAS scales was calculated to form a composite score, which was used in further analyses.

\subsubsection{Depression}

The level of depression was measured by the Beck Depression Inventory II (BDI-II; [4]). The BDI-II contains 21 items scored from 0 to 3 . Total scores are obtained by summing the item scores resulting in total scores ranging from 0 (not depressed at all) to 63 (severely depressed). The questionnaire has good psychometric properties and is a valid questionnaire to measure the severity of depression in patients with chronic pain $[3,14]$.

\subsection{Physical activity assessment}

\subsubsection{Diary assessment of physical activity}

To assess a patient's perception of his/her activity level an electronic diary was used. This self-assessment technique allows multiple random assessments based on the Experience Sampling Method (ESM) [6,7]. Based on this registration method, activity changes over time can be registered, which can overcome the recall bias of a questionnaire [29]. During a 14-day measurement period patients carried a palm-top computer (type palm m100) during waking hours. Patients were instructed that an alarm (beep) would randomly go off eight times a day and at that moment they had to fill in questions. Diary questions were presented on-screen for completion via a touch screen $(50 \times 50 \mathrm{~mm})$ and entries were time and date stamped. A total number of 43 questions were included in each momentary assessment. Two self-constructed questions were directed to assess a patient's physical activity level. The first question was "Right now, I am active." Answer categories were presented in seven point Likert scales ranging from 1, "not at all" to 7, "very". The second question was "What was my effort between this and the previous beep?" Answer categories were 1, lying down; 2, sitting; 3, standing; 4, walking; 5, cycling; 6, sports; 7 , sports vigorously. The maximum number of completed set of palm-top questions for the measurement period is 112 . Patients were instructed to respond to as many beeps as possible.

\subsubsection{Accelerometry}

Physical activity in daily life was assessed by a tri-axial accelerometer (RT3; Stayhealthy Inc., Monrovia, USA). Subjects were instructed to wear the RT3 during waking hours for 14 consecutive days. The accelerometer was not worn during activities in case of potential damage to the equipment (e.g. contact sports, swimming or taking a shower). To be included as a valid score on physical activity in daily life, at least 5 valid measurement days, including 1 weekend day, had to be available [13]. A valid measurement day was defined as a registration period for at least $600 \mathrm{~min}$ $(10 \mathrm{~h})$. Acceleration signals from the three measurement directions (the sagittal, the mediolateral and the longitudinal axes of the trunk) were recorded. The 3D resultant of the acceleration signal was calculated and the number of occasions per minute (counts) on which this signal exceeded a predefined threshold was stored in a database within the accelerometer. Data processing was performed using MATLAB software (The Math Works Inc., Natick, MA). An algorithm was designed in which night time was identified and excluded for further analysis. In this algorithm first, a second order zero time lag low pass Butterworth filter was used to reduce signal noise. Next, a predefined threshold was determined 
to identify start and endpoints in the activity signal. The original signal counts were used for further data processing. The activity signal was processed at the intervals that lay between subsequent beeps of the electronic diary.

\subsection{Procedure}

Prior to participation, all subjects were informed about the purpose of the study and signed a written consent form. Participants completed the self-report measures (containing assessment of disability, habitual physical activity, pain intensity and depression) in a paper-based or computerized internet-based questionnaire. Patients were explained that the interest of the study was to evaluate their daily life functioning and factors that influence their functioning. During a 14-day measurement period patients carried the accelerometer and the palm-top computer simultaneously during waking hours. A short training session on handling both the palm-top and the RT3 was given. During the measurement period stand-by assistance to handle technical problems was available.

\subsection{Data reduction and analysis}

Registration days were only included in case they contained both a valid registration of the accelerometer and the palm-top diary. To check this, first, every day was checked for the availability of a registration time of accelerometer-data of at least $600 \mathrm{~min}$. Subsequently, an additional check was performed on the availability of at least 25 completed ESM reports for all registration days together in which at least $600 \mathrm{~min}$ are registered. For all assessment days that fulfilled both criteria, data of the first completed ESM report of that day were excluded from the final data-file, since answering a question concerning activities since the last beep, on that moment would include a timeframe in which patients were sleeping and not wearing the accelerometer. As a result of this, the maximum achievable number of completed ESM reports in the diary was 98 .

In order to study if patients who are more depressed and experience more pain, also have a lower objectively measured activity level, a two-level hierarchical linear regression analysis was performed. In multilevel modelling the repeated observations (in this model the processed activity signal of the accelerometer) are presented as Level 1 units. These observations were organized within Level 2 units, which constitute persons. A critical feature of Level 1 and Level 2 observations are the independency of Level 1 and Level 2 measurements. This method anticipates on the level of variation within and between patients. In the model physical activity based on accelerometry was the dependent variable and depression and pain intensity were the independent variables.

To analyse the association between the level of physical activity assessed by the diary and by the accelerometer again a two-level hierarchical linear regression analysis was performed. Since we have two diary questions measuring physical activity, two different models were built. In both models self-reported physical activity based on the diary was the dependent variable. The independent variable was physical activity assessed with an accelerometry.

In addition, in order to test the influence of both depression and pain intensity on the discrepancy between the self-reported and objectively assessed physical activity levels, these variables were introduced in a multilevel model. This procedure was performed separately for both diary questions on self-reported physical activity. In each model, the self-reported physical activity variable assessed with the diary and the objectively assessed physical activity variable assessed with the accelerometer were first standardized and then subtracted, resulting in a discrepancy score between the self-reported and objectively assessed level of physical activity in daily life. Both discrepancy scores were the dependent variable in two different models and in both models depression and pain intensity were the independent variables.

Multilevel modelling was performed using Stata 10 software (Stata Corp., 2007, College Station, Texas).

\section{Results}

One hundred and one patients (54 male/47 female) participated in this study and agreed to carry both the palm-top diary and the accelerometer for the assessment of physical activity. Mean age of

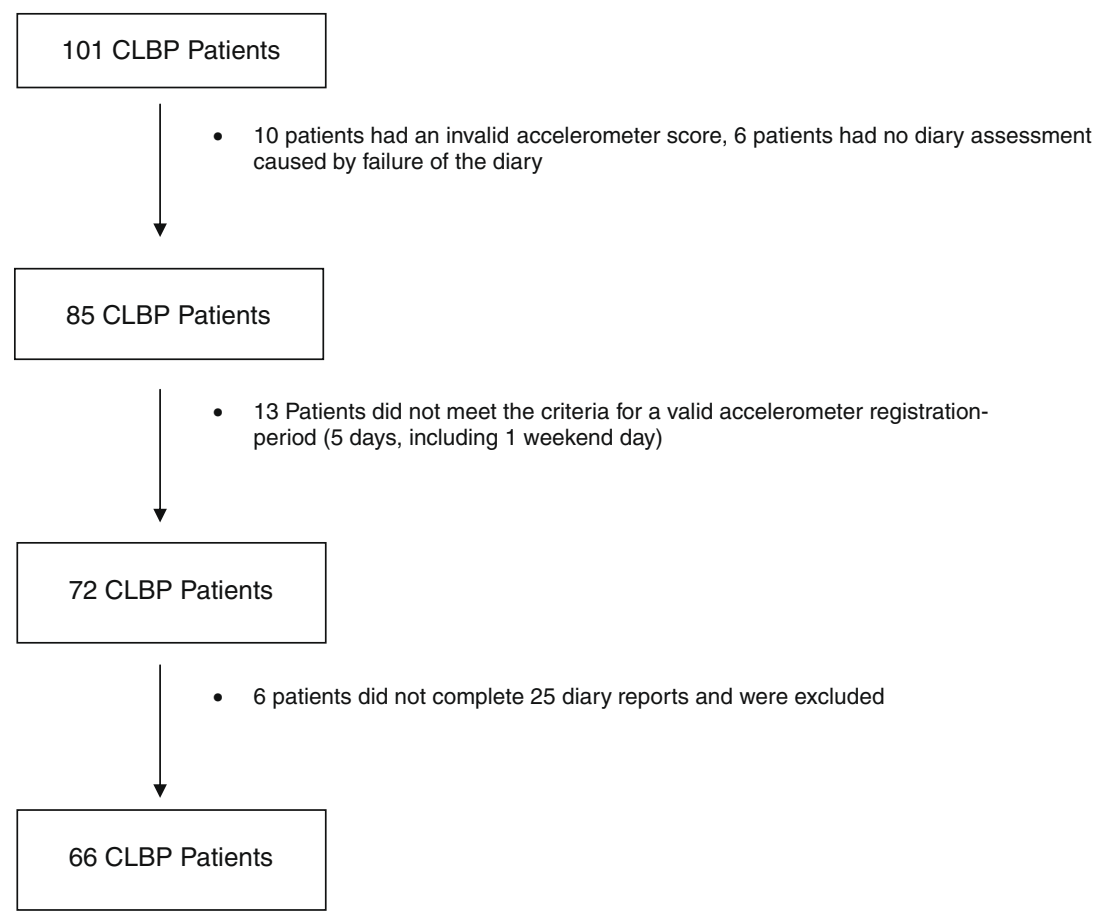

Fig. 1. Flow chart. 
Table 1

Characteristics of the study population of patients with CLBP.

\begin{tabular}{ll} 
Male/female $(N)$ & $37 / 29$ \\
Age (years) & $48.4 \pm 9.9$ \\
Work status ( $N$ and percentage) & \\
$\quad$ Paid job & $34(52 \%)$ \\
Sick leave & $3(8 \%)$ \\
Disability payment & $11(17 \%)$ \\
Disability level $\left(\mathrm{RDQ}^{*}\right)$ & $11.4(4.5)$ \\
Depression (BDI-II*) & $11.0(6.5-15.0)$ \\
Habitual activity level $\left(\mathrm{BPAQ}^{* * *}\right)$ & $8.7(7.6-9.8)$ \\
\hline
\end{tabular}

Normally distributed data are represented by a mean score (SD).

Not normally distributed data are represented by a median score (interquartile ranges).

RDQ, Roland Disability Questionnaire.

*** BDI-II, Beck Depression Inventory II.

*** BPAQ, Baecke Physical Activity Questionnaire.

this group was 47.0 years $(S D=11.0$ ) and $47 \%$ had a paid job. Mean disability level was 11.8 ( $\mathrm{SD}=4.7$ ). In Fig. 1 , a flow chart is shown, representing the data of patients that were eventually used for further analysis in the current study. Overall, the 66 patients that met the criteria set for inclusion filled in $73.1 \%$ of electronic diary assessments. The median Baecke score of the 66 patients included in the final analyses was 8.7 (interquartile range 7.6-9.8). This score is comparable with scores of healthy Dutch individuals [2]. More characteristics of the 66 patients are presented in Table 1. Patients who did not meet the criteria to be included in the data analysis or dropped out of the final analysis due to failure of the diary or palm-top were not significantly different on gender or habitual physical activity level. However, patients who did not meet the criteria for a valid registration were significantly more disabled $(p=0.05)$. Furthermore, patients who had no registration caused by failure of either the diary or the accelerometer were significantly younger.

In Table 2, the multilevel analysis with the objective measured activity level as the dependent variable and depression, and pain intensity as independent variables is shown. No significant associations were found in this model. The association between the selfreported physical activity score based on the item "Right now, I am active." and the objectively assessed activity level based on accelerometry was $\beta=0.21, p<0.01$ (Wald $\chi^{2}=174.94, p<0.01$ ). The association between the item "What was my effort between this and the previous beep?" in the diary and the objectively assessed activity level was $\beta=0.39, p<0.01$ (Wald $\chi^{2}=694.75, p<0.01$ ).

In Table 3, the multilevel analysis with the discrepancy between the self-reported activity score related to the question "What was my effort between this and the previous beep?" and the objectively measured activity level as the dependent variable and depression, and pain intensity as independent variables is shown. A significant association was found between depression and the discrepancy score $(\beta=-0.19, p=0.01)$, whereas pain intensity did not contribute significantly. In addition, the second model with the discrepancy between the score on the diary item "Right now, I think I am active." and the objectively assessed activity level as dependent variable showed similar results. In this last model, the Wald $\chi^{2}$ appeared to be $7.15, p<0.05$. Depression was found to be significantly associated with the discrepancy score $(\beta=-0.22, p=0.01)$ whereas pain intensity did not $(\beta=0.14, \mathrm{~ns})$.

Table 2

Multilevel analysis with the objective activity in daily life level as dependent variable.

\begin{tabular}{llrlrl}
\hline \multirow{5}{*}{ Wald $\chi^{2}=3.22, p=0.20$} \\
\cline { 2 - 6 } & Main effects & \multicolumn{1}{l}{$\beta$} & \multicolumn{1}{l}{ SE } & \multicolumn{1}{l}{$Z$} & \multicolumn{1}{l}{$P$} \\
\hline Objective activity level & Pain intensity & -0.08 & 0.06 & -1.25 & 0.21 \\
& Depression & 0.10 & 0.06 & 1.69 & 0.09 \\
\hline
\end{tabular}

Table 3

Multilevel analysis with the discrepancy between the self-reported activity level and the objectively assessed activity level as dependent variable.

\begin{tabular}{|c|c|c|c|c|c|}
\hline & \multicolumn{5}{|c|}{ Wald $\chi^{2}=6.58, p<0.05$} \\
\hline & Main effects & $\beta$ & SE & $Z$ & $P$ \\
\hline \multirow[t]{2}{*}{$\begin{array}{l}\text { Subjective-Objective activity } \\
\text { level }\end{array}$} & $\begin{array}{l}\text { Pain } \\
\text { intensity }\end{array}$ & 0.12 & 0.08 & 1.54 & 0.12 \\
\hline & Depression & -0.19 & 0.08 & -2.50 & 0.01 \\
\hline
\end{tabular}

\section{Discussion}

This study aimed at evaluating the extent to which higher levels of depression and pain experience are associated with a lower daily life activity level in patients with CLBP. Furthermore, the influence of pain intensity and depression on the discrepancy between the self-reported level of physical activity and the objective measured activity level was tested.

In this study, depression was not associated with the objectively assessed level of physical activity. But patients that were more depressed reported a relatively lower level of physical activity in daily life as compared to their actual level of physical activity. Consequently, depression was significantly associated with the discrepancy between self-reported and objectively assessed physical activity in daily life significantly. This finding seems in accordance with results of a study of Kremer et al. who found that patients who were more depressed underreported their activity level as compared to the observed activity level by staff members [17]. Furthermore, Wittink et al. found that the score on the mental health domain of the SF-36, measuring quality of life, of patients with CLBP was not associated with their performance on a treadmill, although patients with lower scores on the mental health domain reported a higher level of pain intensity and a lower level of physical functioning [32]. In contrast to the lack of association between depression and the objectively assessed daily life activity level in the present and another study [11], several studies reported a negative influence of depression on physical performance and physical capacity testing in patients with CLBP $[1,22,28]$. However, this negative influence of depression on physical activity measured in a standardized laboratory setting with a performance or capacity test could not be determined when physical activity is measured during actual daily life activities. Based on the findings of this study, it could be hypothesized that a depressed mood can distort a patients' view on his/her own activities. Although depression and actual level of daily life activity are not related, the influence of depression seems especially focussed on the discrepancy between perceived and actual level of physical activity. In interpreting this, it should however be taken into account that the median BDI-II score for depression in the current study was only 11.0 (interquartile range 6.5-15.0), which is below the cut-off score for moderate clinical depression of 20 [14].

Based on the results of the current study, it appeared that pain intensity was not associated with a patient's actual daily life activity level. Furthermore, we hypothesized that a higher score on pain intensity would distort a patient's view of their actual activity level, resulting in a higher discrepancy between actual and perceived level of physical activity. In earlier studies using self-report as outcome measure for physical activity, the association between pain intensity and physical activity was indeed found $[10,15]$. However, in studies using objective daily life activity measurements or performance testing as outcome assessments for physical activity these results could not be confirmed [1,9,19,25,31]. In the current study, both subjective and objective assessments of physical activity were included. The assumption that a higher level of pain intensity would have a negative impact on the discrepancy 
between a patient's perception and the objectified registration of his/her level of physical activity in daily life could however not be confirmed based on these data.

In the current study, a diary assessment was used. A drawback of this assessment is that in one question limited information can be asked for. Therefore, in this study two questions that measure different aspects of physical activity in daily life were evaluated to answer the research questions. One diary question ("What was my effort between this and the previous beep?") asked for the quality of movements (such as walking and cycling), whereas the other question ("Right now, I am active.") asked for the level of intensity.

The current study has some limitations that have to be addressed. The first limitation is the absence of a continuous accelerometry registration due to swimming or being involved in contact sports. This means that the accelerometer has to be taken off which can result in an underestimation of a patient's actual activity level. In the current study, all patients were asked to register when they had to remove the accelerometer. Nine of the 66 patients reported indeed an interruption of their activity registration due to swimming or performing contact sports. Four of them removed the accelerometer for more than $4 \mathrm{~h}$. Since it seemed highly unlikely that they were continuously swimming, imputation would have resulted in an overestimation of a patient's actual activity level. For the other 5 patients, data were imputed with two times the mean score per minute of the previous day which resulted in only a small increase of maximal $3 \%$. Based on this, we eventually decided to abandon imputation for swimming or contact sports.

A second limitation is that the number of patients had to be excluded. The sample size was reduced to 66 patients. The data of 35 patients could not be used for the final analysis: 16 had an invalid RT3 score or problems with the electronic diary, and the data of 19 patients did not meet the predefined data selection criteria. In this study, it appeared that patients who had a registration that did not fulfill the data selection criteria were significantly more disabled. Focusing on this drop-out group revealed that two extreme disability scored 21 , with a mean score of $11.4(S D=4.5)$ for the 66 included participants. As a result of this, inclusion of these two patients would disturb a valid presentation of an objective daily life activity level. Even though we used this strict criteria, the sample size in the present study is still higher than in other studies evaluating daily life activities in patients with CLBP [15,19,31].

This study has clinical implications. In evaluating a patient's level of activity based on self-report (for instance, as a part of an anamnesis during a clinical consultation or based on a questionnaire as a part of an assessment tool) differences between the activity level as reported by a patient and his/her actual level of physical activity have to be taken into account. Especially in patients who are depressed, an underestimation of a patient's actual activity level has to be taken in mind. Based on this, generalization of results on physical activity retrieved based on self-report to a situation of daily life functioning should be performed with caution. Furthermore, in evaluating treatment, it is important to measure physical activity in daily life objectively because changes in mood during therapy can also influence a patient's perception over time of his/her activity level.

In summary, in the current study it was shown that patients with CLBP, who had a higher level of depression, underestimated their daily activity level, although their actual activity level did not differ.

\section{Acknowledgements}

This study was supported by the Council for Medical and Health Research of The Netherlands(ZON-MW), Grant No. 14350042. Participation of Dr. Roelofs was supported by the EFIC-GrünenthalGrant (EGG). The authors thank Sita van Riet, Astrid Dello and
Truus Custers for their contribution in the data collection. We are also grateful to all physicians referring patients to our study, and to the patients willing to participate. The authors have no conflicts of interest relevant to this work.

\section{References}

[1] Alschuler KN, Theisen-Goodvich ME, Haig AJ, Geisser ME. A comparison of the relationship between depression, perceived disability, and physical performance in persons with chronic pain. Eur J Pain 2008;12:757-64.

[2] Baecke JA, Burema J, Frijters JE. A short questionnaire for the measurement of habitual physical activity in epidemiological studies. Am J Clin Nutr 1982;36:936-42.

[3] Beck AT, Steer RA, Brown GK. Manual for the Beck Depression Inventory. 2nd ed. San Antonio, TX: The Psychological Corporation; 1996.

[4] Beck AT, Steer RA, Brown GK, Van der Does AJW. BDI-II-NL Handleiding (BDI-IIDutch manual). Lisse, The Netherlands: Psychological Corporation; 2002.

[5] Brouwer S, Kuijer W, Dijkstra PU, Goeken LN, Groothoff JW, Geertzen JH. Reliability and stability of the Roland-Morris Disability Questionnaire: intra class correlation and limits of agreement. Disabil Rehabil 2004;26:162-5.

[6] Csikszentmihalyi M, Larson R. Validity and reliability of the ExperienceSampling Method. J Nerv Ment Dis 1987;175:526-36.

[7] Delespaul PAEG. Assessing schizophrenia in daily life. Maastricht: Universitaire Press; 1995.

[8] Faas A, Chavannes AW, Koes BW, van den Hoogen JMM, Mens JMA, Smeele LJM, Romeijnders ACM, van der Laan JR. NHG-standaard M54 lage-rugpijn; 1996.

[9] Filho IT, Simmonds MJ, Protas EJ, Jones S. Back pain, physical function, and estimates of aerobic capacity: what are the relationships among methods and measures? Am J Phys Med Rehabil 2002;81:913-20.

[10] Fordyce WE, Lansky D, Calsyn DA, Shelton JL, Stolov WC, Rock DL. Pain measurement and pain behavior. Pain 1984;18:53-69.

[11] Geisser ME, Haig AJ, Theisen ME. Activity avoidance and function in persons with chronic back pain. J Occup Rehabil 2000;10:215-27.

[12] Gommans JHB, Koes BW, van T MW. Validiteit en responsiviteit Nederlandstalige Roland Disability Questionnaire. Vragenlijst naar functionele status bij patienten met lage rugpijn. nederlands tijdschrift voor fysiotherapie 1999; 1997:107;2:28-33.

[13] Gretebeck RJ, Montoye HJ. Variability of some objective measures of physical activity. Med Sci Sports Exerc 1992;24:1167-72.

[14] Harris CA, D’Eon JL. Psychometric properties of the Beck Depression Inventory - second edition (BDI-II) in individuals with chronic pain. Pain 2008;137:609-22.

[15] Hasenbring MI, Plaas H, Fischbein B, Willburger R. The relationship between activity and pain in patients 6 months after lumbar disc surgery: do painrelated coping modes act as moderator variables? Eur J Pain 2006;10:701-9.

[16] Jacob T, Baras M, Zeev A, Epstein L. Low back pain: reliability of a set of pain measurement tools. Arch Phys Med Rehabil 2001;82:735-42.

[17] Kremer EF, Block A, Gaylor MS. Behavioral approaches to treatment of chronic pain: the inaccuracy of patient self-report measures. Arch Phys Med Rehabil 1981;62:188-91.

[18] Kuijer W, Brouwer S, Dijkstra PU, Jorritsma W, Groothoff JW, Geertzen JH. Responsiveness of the Roland-Morris Disability Questionnaire: consequences of using different external criteria. Clin Rehabil 2005;19:488-95.

[19] Liszka-Hackzell JJ, Martin DP. An analysis of the relationship between activity and pain in chronic and acute low back pain. Anesth Analg 2004;99:477-81 [table of contents].

[20] Merskey H, Bogduk N. Classification of chronic pain. In: IASP Task force on taxonomy. 2nd ed. Seattle: IASP Press; 1994.

[21] Miller DJ, Freedson PS, Kline GM. Comparison of activity levels using the Caltrac accelerometer and five questionnaires. Med Sci Sports Exerc 1994;26:376-82.

[22] Novy DM, Simmonds MJ, Lee CE. Physical performance tasks: what are the underlying constructs? Arch Phys Med Rehabil 2002;83:44-7.

[23] Philippaerts RM, Westerterp KR, Lefevre J. Comparison of two questionnaires with a tri-axial accelerometer to assess physical activity patterns. Int J Sports Med 2001;22:34-9.

[24] Price DD, McGrath PA, Rafii A, Buckingham B. The validation of visual analogue scales as ratio scale measures for chronic and experimental pain. Pain 1983:17:45-56.

[25] Reneman MF, Schiphorts Preuper HR, Kleen M, Geertzen JH, Dijkstra PU. Are pain intensity and pain related fear related to functional capacity evaluation performances of patients with chronic low back pain? J Occup Rehabil 2007; 17:247-58.

[26] Roland M, Morris R. A study of the natural history of back pain. Part I: Development of a reliable and sensitive measure of disability in low-back pain. Spine 1983;8:141-4.

[27] Roland M, Morris R. A study of the natural history of low-back pain. Part II: Development of guidelines for trials of treatment in primary care. Spine 1983;8:145-50.

[28] Smeets RJ, van Geel AC, Kester AD, Knottnerus JA. Physical capacity tasks in chronic low back pain: what is the contributing role of cardiovascular capacity, pain and psychological factors? Disabil Rehabil 2007;29:577-86. 
[29] Stone AA, Broderick JE. Real-time data collection for pain: appraisal and current status. Pain Med 2007;8:S85-93.

[30] van der Ploeg HP, Streppel KR, van der Beek AJ, van der Woude LH, Vollenbroek-Hutten $M$, van Mechelen $W$. The physical activity scale for individuals with physical disabilities: test-retest reliability and comparison with an accelerometer. J Phys Act Health 2007;4:96-100.
[31] Verbunt JA, Westerterp KR, van der Heijden GJ, Seelen HA, Vlaeyen JW, Knottnerus JA. Physical activity in daily life in patients with chronic low back pain. Arch Phys Med Rehabil 2001;82:726-30.

[32] Wittink H, Rogers W, Sukiennik A, Carr DB. Physical functioning: self-report and performance measures are related but distinct. Spine 2003;28:2407-13. 